\title{
Lymph Node Yield Following Packet Submission After Isolation By Surgeon During Gastrectomy
}

This article was published in the following Dove Press journal:

Cancer Management and Research

\author{
Pengpeng Wang ${ }^{1,2}$ \\ Kecheng Zhang ${ }^{2}$ \\ Hongqing $\mathrm{Xi}^{2}$ \\ Wenquan Liang $\left(\mathbb{D}^{2}\right.$ \\ Tianyu Xie ${ }^{1,2}$ \\ Yunhe Gao ${ }^{2}$ \\ Bo Wei ${ }^{2}$ \\ Lin Chen ${ }^{1,2}$ \\ 'School of Medicine, Nankai University, \\ Tianjin 30007I, People's Republic of \\ China; ${ }^{2}$ Department of General Surgery, \\ Chinese People's Liberation Army \\ General Hospital, Beijing 100853 , \\ People's Republic of China
}

Correspondence: Bo Wei; Lin Chen Department of General Surgery, Chinese People's Liberation Army General Hospital, Fuxing Road 28\#, Haidian District, Beijing 100853, People's Republic of China

Email weibo@vip.163.com;

chenlin@30Ihospital.com.cn

\begin{abstract}
Purpose: To compare the lymph node yields of lymph node packet submission (PS), packet submission after isolation by surgeons (PSI), and en bloc lymph node submission (EBS) after gastrectomy.

Methods: We conducted a prospective study including 118 gastric cancer patients who underwent gastrectomy between June 2016 and August 2016. We also retrospectively reviewed 607 patients who underwent gastrectomy from May 2015 to May 2016. Following gastrectomy, lymph node specimens were either submitted en bloc (EBS group), divided into packets with accompanying adipose tissue according to the lymph node stations (PS group), or isolated individually based on the surgeon's visualization and palpation before submission to the Pathology Department (PSI group).

Results: The average lymph node yield was significantly higher in the PSI compared with the PS group in the prospective study $(46.5 \pm 19.4$ vs $31.8 \pm 11.1)$, and significantly higher in the PS compared with the EBS group in the retrospective study $(31.5 \pm 12.6$ vs $23.9 \pm 8.9)$ (both $\mathrm{P}<0.001$ ). There was no significant difference in positive lymph node yields in either of these comparisons (prospective study, $\mathrm{P}=0.581$; retrospective study, $\mathrm{P}=0.489$ ). The survival curve indicated no significant difference between the PS and PSI groups ( $\log$ rank $\mathrm{P}=0.957$ ); however, these three groups share different lymph node ratio (LNR).

Conclusion: PSI could yield more lymph nodes than PS or EBS with a lower LNR at pathological examination. However, the difference in lymph nodes harvested had no impact on survival, which may need further investigation.
\end{abstract}

Keywords: lymph node retrieval, lymph node, gastric cancer, gastrectomy, cancer staging

\section{Introduction}

Gastric cancer is one of the most prevalent cancers and main causes of cancerrelated deaths worldwide, ranking fifth in terms of morbidity and third in terms of mortality. ${ }^{1}$ A database indicated that an estimated 6.7 million new cases of cancer were diagnosed in older adults in 2012, wherein gastric cancer stands in fourth place; the incidence is expected to expand substantially by 2035 according to calculation and prediction, which will bring considerable and unique challenges to health systems. ${ }^{2}$ Gastric cancer has a poor prognosis, with a 5-year survival rate of $<25 \%{ }^{3}$ Most confirmed clinical cases involve progressive gastric cancer, and surgery remains the mainstay of combined treatment.

More than half of all gastric cancer patients have lymph node metastases at their initial diagnosis or before surgical treatment, which contributes to the generally poor prognosis. ${ }^{4}$ The number of lymph node metastases is an important indicator for clinical staging; it can help to evaluate the quality of the surgery and can also 
influence postoperative treatment strategies. Several studies have shown that patients with negative lymph node metastasis have a better prognosis than those with lymph node metastasis, ${ }^{5-7}$ and the prognosis of patients without lymph node metastasis may improve when more lymph nodes are examined. ${ }^{8}$ Furthermore, the number of positive lymph nodes can be used as an independent prognostic factor for overall and disease-free survival. ${ }^{9}$ During surgery, gastric resection and corresponding lymph node dissection are important factors affecting the success of radical gastrectomy and reducing postoperative recurrence. The 2017 edition of the National Comprehensive Cancer Network Guidelines pointed out that gastric resection should include the regional lymphatics-perigastric lymph nodes (D1) and those along the named vessels of the celiac axis (D2), with the goal of examining at least 15 lymph nodes. However, there is currently no widely recognized standard in terms of the appropriate number of lymph nodes required for accurate staging of gastric cancer. The recommendation of detecting at least 15 lymph nodes is based on avoiding staging migration, but the use of this criterion to evaluate patient prognosis remains controversial. ${ }^{10,11}$

Our center routinely performs D2 radical surgery for patients with operable gastric cancer. En bloc lymph node submission (EBS) was initially carried out for the pathological analysis of gastric cancer specimens in the early years, but given that the number of lymph nodes provided was relatively low, this procedure was replaced with lymph node packet submission (PS), which increased the average number of lymph nodes harvested to above that reported in a study in the United States, but still lower than reported in a Japanese study. ${ }^{12,13}$ However, very few cases reported fewer than 15 lymph nodes for postoperative pathological examination after PS. Based on previous data analysis, we therefore introduced packet submission after isolation by surgeons (PSI).

In this study, we compared the numbers of lymph nodes harvested and numbers of positive lymph nodes detected following EBS, PS, and PSI, to explore the balance between accurate positive lymph node acquisition and the efficiency of specimen handling.

\section{Methods}

This research comprised a retrospective study and a prospective study. The retrospective study involved patients who underwent gastric cancer surgery during the period when our center performed EBS and PS, and the prospective study was conducted to compare the difference in numbers of lymph nodes detected between the PS and PSI procedures.

\section{Patients}

All of the patients were diagnosed with gastric carcinoma and underwent radical gastrectomy at the Chinese People's Liberation Army General Hospital. The study was approved by the Chinese PLA General Hospital Institutional Review Board and Ethics Committee. Written informed consent was obtained from all patients for the prospective study, and patient written informed consent in the retrospective study was waived due to its retrospective nature. All procedures were conducted in accordance with the guidelines of the hospital's ethics committee and the Declaration of Helsinki. The data included in this research was kept anonymous and confidential. The retrospective study included 607 patients who underwent surgery from May 2015 to May 2016, including 168 in the EBS group and 439 in the PS group. All surgeons were well trained with at least 5 years of surgical experience. The prospective study enrolled 118 patients (59 each in the PS and PSI groups) who underwent surgery from June 2016 to August 2016. Patient-related data included gender, age, hospitalization days (HOD), postoperative days (POD), and body mass index (BMI). Surgery-related data included surgeon's experience, gastrectomy selection (subtotal or total), mode of operation (open or laparoscopic), duration of operation, and surgical blood loss. Pathology-related data included tumor size, location (upper, median, lower), histological classification (well differentiated, G1; moderately differentiated, G2; poorly differentiated, G3), T stage, $\mathrm{N}$ stage, pathological stage, number of lymph nodes harvested, and number of positive lymph nodes.

\section{Details Of EBS, PS, And PSI}

In the EBS group, specimens were stored in formalin solution after surgical en bloc dissection and then sent to the Pathology Department for further examination. In the PS group, specimens were processed with the accompanying adipose tissue and divided immediately into different packets according to the lymph node stations noted in the 13th Japanese Classification of Gastric Carcinoma, after surgical dissection. All divided specimens were stored and sent to the Pathology Department separately. In the PSI group, specimens were processed into different groups similarly to the aforementioned PS procedure, but the lymph nodes were isolated and sorted individually based on visual 
examination and palpation by the surgeons and/or welltrained assistants before submission to the Pathology Department (Figure 1). All of the isolated specimens were also isolated and sorted by pathology assistants in the Pathology Department. Lymph node metastasis was diagnosed using single-plane examination, and immunohistochemistry was carried out in poorly differentiated cases.

\section{Statistical Analysis}

Data are displayed as the mean \pm SD. Categorical variables were compared using the chi-squared test. Continuous variables were analyzed using the normality test and variance homogeneity test to determine whether they conformed to a normal distribution and to demonstrate homogeneity of variance. A two-sample $t$-test or Mann-Whitney $U$-test were selected according to the test results. Overall survival was analyzed using the KaplanMeier method. Graphs were drawn using GraphPad Prism version 7. The null hypothesis was rejected when $\alpha<0.05$, and $\mathrm{P}<0.05$ was regarded as a significant difference.

\section{Results}

\section{Retrospective Study}

The patient-, surgery-, and pathology-related data for patients in the retrospective study are shown in Table 1. There was no significant difference between the EBS and PS groups in terms of individual factors including gender, BMI, HOD, or POD, or in surgery-related variables including surgeon's experience and gastrectomy selection $(\mathrm{P}>0.05)$. However, patients in the EBS group were significantly older than those in the PS group $(59.4 \pm 10.7$ vs $57.1 \pm 11.3$ years; $\mathrm{P}=0.026$ ). There were also significant differences between the groups in terms of mode of operation $(\mathrm{P}<0.001)$, duration of operation $(\mathrm{P}<0.001)$, and surgical blood loss $(\mathrm{P}=0.013)$. Regarding the pathological results, there was no significant difference between the two groups in terms of tumor size, histological classification, $\mathrm{T}$ or $\mathrm{N}$ stage, or pathological stage $(\mathrm{P}>0.05)$. However, there was a significant difference in tumor location $(\mathrm{P}=0.024)$ (Table 1$)$.

The average number of lymph nodes harvested was significantly higher in the PS group than in the EBS group (31.5 \pm 12.6 vs 23.9 $\pm 8.9 ; \mathrm{P}<0.001)$ (Figure 2A). However, there was no significant difference in the average number of positive lymph nodes between the PS and EBS groups (5.0 \pm 8.3 vs $4.5 \pm 6.3 ; \mathrm{P}=0.489$ ) (Figure $2 \mathrm{~B}$ ). The correlation between the number of lymph nodes harvested and positive lymph nodes harvested in the retrospective study is illustrated in Figure 2C-D. We further investigated the minimum average lymph node diameter in the EBS and PS groups, which showed a significant difference between the two groups $(\mathrm{P}<0.001)$ (Figure 2E), the average diameter in the PS group being lower than that in the EBS group.

PS harvested significantly more lymph nodes than EBS in patients stratified according to sex, age ( $<60$ or $\geq 60$ years), BMI ( $<27$ or $\geq 27$ ), surgeon's experience, gastrectomy selection, mode of operation, and tumor location. The average number of lymph nodes harvested was also significantly higher in the PS group compared with the EBS group in relation to $\mathrm{T}, \mathrm{N}$, and pathological stage (Table 2). Furthermore, significantly more patients in the PS group had at least 25 lymph nodes harvested compared with the EBS group (67.2\% vs 44\%, respectively; $\mathrm{P}<0.001$ ).

\section{Prospective Study}

The patient-, surgery-, and pathology-related variables for patients in the PS and PSI groups in the prospective study are listed in Table 3. There was no significant difference between the two groups in terms of individual factors including gender, age, HOD, POD, BMI, or in surgery-related factors including surgeon's experience, gastrectomy selection,
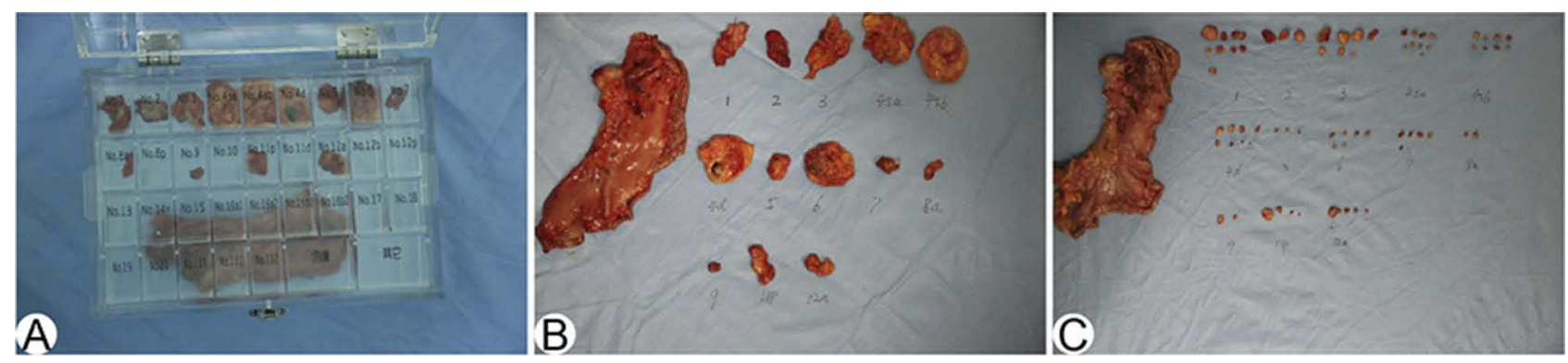

Figure I PS and PSI specimen sorting. (A) Processed specimens in sorting box. (B) Lymph node packet submission specimens sorted into lymph node stations. (C) Packet submission after isolation by surgeons sorted into lymph node stations. 
Table I Gastric Cancer-Relevant Variables In The EBS Group And PS Group

\begin{tabular}{|c|c|c|c|}
\hline & EBS Group $(N=\mid 68)$ & PS Group ( $N=439)$ & $P$ value \\
\hline \multicolumn{4}{|l|}{ Patient-related data } \\
\hline Male, n (\%) & $123(73.2 \%)$ & 308 (70.2\%) & 0.458 \\
\hline Female, n (\%) & $45(26.8 \%)$ & $|3|(29.8 \%)$ & \\
\hline Age (years) & $59.4 \pm 10.7$ & $57.1 \pm 11.3$ & 0.026 \\
\hline HOD (days) & $18.3 \pm 8.6$ & $17.9 \pm 10.8$ & 0.247 \\
\hline POD (days) & $12 \pm 7.1$ & $12.1 \pm 10$ & 0.088 \\
\hline BMI $\left(\mathrm{kg} / \mathrm{m}^{2}\right)$ & $24 \pm 3.6$ & $24 \pm 3.3$ & 0.967 \\
\hline \multicolumn{4}{|l|}{ Surgery-related data } \\
\hline Surgeon's experience ( $\geq 15$ years) & 132 & 324 & 0.224 \\
\hline \multicolumn{4}{|l|}{ Gastrectomy selection, n (\%) } \\
\hline Subtotal & $108(64.3 \%)$ & $292(66.5 \%)$ & 0.604 \\
\hline Total & $60(35.7 \%)$ & 147 (33.5\%) & \\
\hline \multicolumn{4}{|l|}{ Mode of operation, n (\%) } \\
\hline Open & $|3|(78 \%)$ & $187(42.6 \%)$ & $<0.001$ \\
\hline Laparoscopic & $37(22 \%)$ & $252(57.4 \%)$ & \\
\hline Duration of operation (min) & $191.3 \pm 53.7$ & $224.8 \pm 59.6$ & $<0.001$ \\
\hline Surgical blood loss (mL) & $272 \pm 453.8$ & $210.7 \pm 272.1$ & 0.013 \\
\hline Tumor size $(\mathrm{cm})$ & $4.7 \pm 2.8$ & $4.3 \pm 2.6$ & 0.105 \\
\hline \multicolumn{4}{|l|}{ Tumor location, n (\%) } \\
\hline Upper third & $37(22 \%)$ & $63(14.4 \%)$ & 0.024 \\
\hline Median third & $47(28 \%)$ & $108(24.6 \%)$ & \\
\hline Lower third & $84(50 \%)$ & $268(61 \%)$ & \\
\hline \multicolumn{4}{|l|}{ T stage, n (\%) } \\
\hline TI & 37 (22\%) & $129(29.4 \%)$ & 0.324 \\
\hline $\mathrm{T} 2$ & $23(13.7 \%)$ & $58(13.2 \%)$ & \\
\hline $\mathrm{T} 3$ & $95(56.5 \%)$ & $219(49.9 \%)$ & \\
\hline $\mathrm{T} 4$ & $13(7.7 \%)$ & $33(7.5 \%)$ & \\
\hline \multicolumn{4}{|l|}{$\mathrm{N}$ stage, $\mathrm{n}(\%)$} \\
\hline No & 69 (4I.1\%) & 191 (43.5\%) & 0.756 \\
\hline $\mathrm{NI}$ & $23(13.7 \%)$ & 69 (I5.7\%) & \\
\hline N2 & $31(18.5 \%)$ & 77 (I7.5\%) & \\
\hline N3 & 45 (26.8\%) & $102(23.2 \%)$ & \\
\hline \multicolumn{4}{|l|}{ Histological classification, n (\%) } \\
\hline $\mathrm{GI}+\mathrm{G} 2$ & $74(44 \%)$ & $196(44.6 \%)$ & 0.894 \\
\hline $\mathrm{G} 3$ & $94(56 \%)$ & $243(55.4 \%)$ & \\
\hline \multicolumn{4}{|l|}{ Pathological stage, n (\%) } \\
\hline I & $45(26.8 \%)$ & 140 (31.9\%) & 0.156 \\
\hline II & $50(29.8 \%)$ & $145(33 \%)$ & \\
\hline III & $73(43.4 \%)$ & $154(35.1 \%)$ & \\
\hline
\end{tabular}

Abbreviations: HOD, hospitalization days; POD, postoperative days; BMI, body mass index.

mode of operation, duration of operation, or surgical blood loss $(\mathrm{P}>0.05)$. There was also no significant difference in pathological examination results in terms of tumor size, location, and histological classification, or in $\mathrm{T}, \mathrm{N}$, or pathological stage $(\mathrm{P}>0.05)$ (Table 3).
The average number of lymph nodes harvested in the PSI group was significantly higher than in the PS group (46.5 \pm 19.4 vs $31.8 \pm 11.1 ; \mathrm{P}<0.001$ ) (Figure $3 \mathrm{~A}$ ). However, there was no significant difference in the average number of positive lymph nodes between the two groups $(7.3 \pm 11.8$ 
A

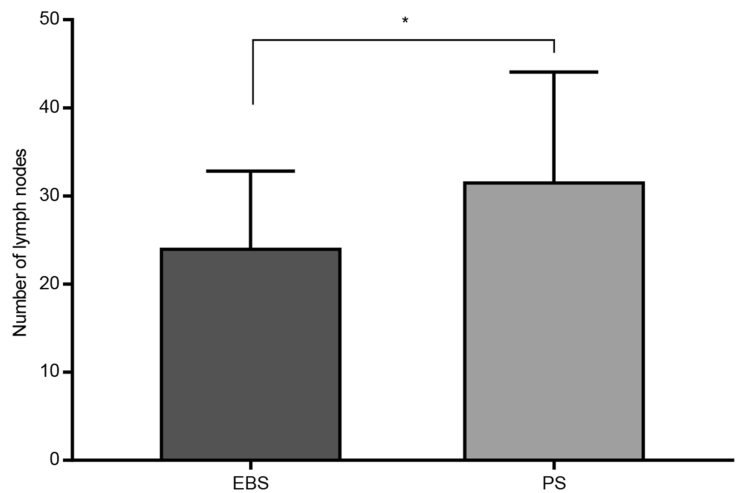

C

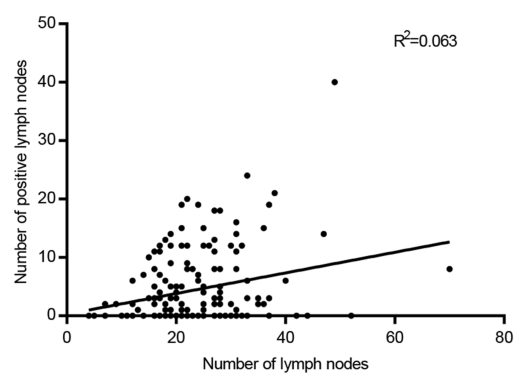

B

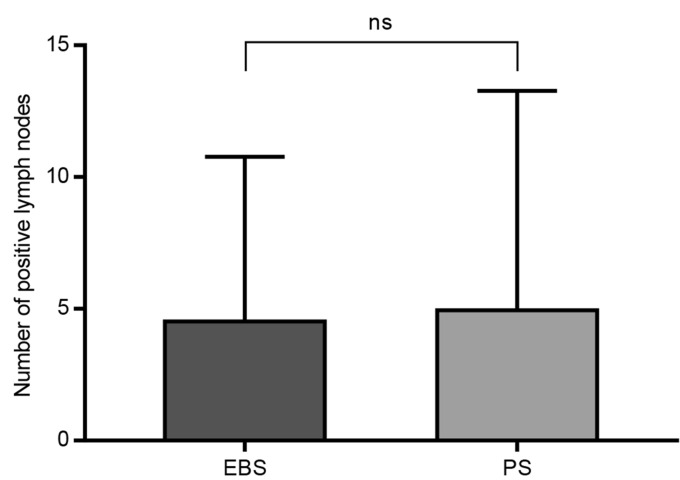

E

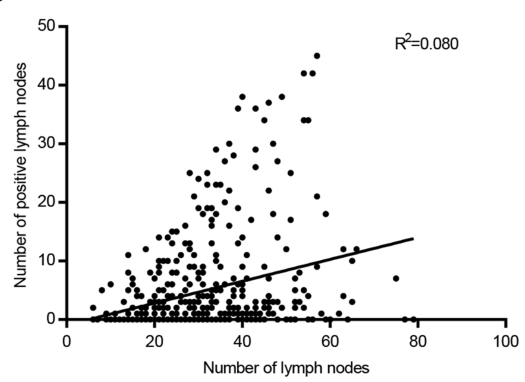

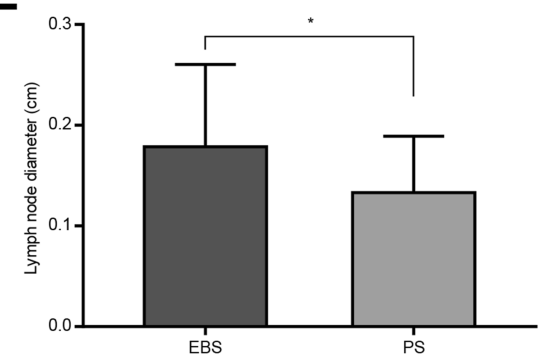

Figure 2 Lymph nodes harvested in EBS and PS groups. (A and B): Average number of lymph nodes harvested in EBS and PS groups (*P<0.05). (C and $\mathbf{D})$ Correlation between the number of lymph node harvested and positive lymph node harvested in EBS and PS groups. (E) The minimum average lymph node diameter in EBS and PS groups $(* \mathrm{P}<0.05)$.

vs $7.7 \pm 10.8$, respectively; $\mathrm{P}=0.581$ ) (Figure $3 \mathrm{~B}$ ). These results indicated that the PSI procedure resulted in harvesting of more lymph nodes for pathological examination in comparison with PS, but did not significantly affect the detection of positive lymph nodes. The correlation between the number of lymph nodes harvested and positive lymph nodes harvested in the prospective study is illustrated in Figure 3C-D. No significant difference was found in the minimum average lymph node diameter between the PS and PSI groups $(\mathrm{P}=0.872)$ (Figure 3E). We further analyzed the number of lymph nodes harvested from different lymph node stations and found a significantly higher yield of lymph nodes in the PSI group than in the PS group from stations $1,3,5$ and $2,4,6(\mathrm{P}=0.006$ and $\mathrm{P}=0.001$, respectively), but not $7,8,9$ and $10,11,12$ and others $(\mathrm{P}=0.142$ and $\mathrm{P}=0.06$, respectively). There was no significant difference in overall survival in the PS and PSI groups after 33 months of follow-up (log rank $\mathrm{P}=0.957$ ) (Figure 4).

PSI harvested significantly more lymph nodes than PS in men and patients aged $\geq 60$ years, as well as in patients stratified according to BMI $(<27$ and $\geq 27)$, surgeon's experience, gastrectomy selection, mode of operation, and tumor location. However, there was no significant difference between the procedures in women and in patients aged $<60$ years. The average number of lymph nodes harvested was significantly higher in the PSI group than in the PS group in relation to $\mathrm{T}, \mathrm{N}$, and pathological stage (Table 4). Notably, more patients in the PSI group had at least 25 lymph nodes harvested compared with the PS group (89.8\% vs $72.9 \% ; \mathrm{P}=0.018)$.

\section{Numbers Of Lymph Nodes Harvested And Lymph Node Ratio}

The lymph node ratio (LNR) is the proportion of positive lymph nodes at postoperative pathological examination relative to the total number of lymph nodes harvested. The study included a total of 725 clinical cases, and we further analyzed the average and median numbers of lymph nodes harvested as well as the LNR in lymph node-positive cases. The average (median) numbers of lymph nodes harvested were 48.8 (51.5) and the average (median) LNRs were 0.256 (0.171) in the PSI group, 33.4 (32) and $0.274(0.167)$ in the PS group, and 24.6 (23) and 
Table 2 Lymph Node Counts Stratified By Relevant Variables In The EBS Group And PS Group

\begin{tabular}{|c|c|c|c|}
\hline & $\begin{array}{l}\text { EBS Group } \\
(N=168)\end{array}$ & $\begin{array}{l}\text { PS Group } \\
(N=439)\end{array}$ & $P$ value \\
\hline Lymph node counts & $23.9 \pm 8.9$ & $31.5 \pm 12.6$ & $<0.001$ \\
\hline Male & $22.2 \pm 8.6$ & $30.6 \pm 12.2$ & $<0.001$ \\
\hline Female & $28.6 \pm 7.9$ & $33.4 \pm 13.5$ & 0.025 \\
\hline Age $<60$ & $24.4 \pm 7.9$ & $31.3 \pm 12.6$ & $<0.001$ \\
\hline Age $\geq 60$ & $23.6 \pm 9.6$ & $31.6 \pm 12.6$ & $<0.001$ \\
\hline BMI $<27$ & $24.3 \pm 9.4$ & $31.6 \pm 12.5$ & $<0.001$ \\
\hline $\mathrm{BMI} \geq 27$ & $22.4 \pm 6.5$ & $31 \pm 13.3$ & 0.001 \\
\hline $\begin{array}{l}\text { Surgeon's experience } \\
\text { ( } \geq 15 \text { years) }\end{array}$ & $23.6 \pm 8.4$ & $31.3 \pm 13$ & $<0.001$ \\
\hline $\begin{array}{l}\text { Surgeon's experience } \\
(<15 \text { years })\end{array}$ & $25.3 \pm 10.4$ & $32 \pm 11.6$ & 0.002 \\
\hline $\begin{array}{l}\text { Gastrectomy selection } \\
\text { Subtotal } \\
\text { Total }\end{array}$ & $\begin{array}{l}23.3 \pm 9.2 \\
25.1 \pm 8.2\end{array}$ & $\begin{array}{l}29.8 \pm 11.7 \\
34.8 \pm 13.7\end{array}$ & $\begin{array}{l}<0.001 \\
<0.001\end{array}$ \\
\hline $\begin{array}{l}\text { Mode of operation } \\
\text { Open } \\
\text { Laparoscopic }\end{array}$ & $\begin{array}{l}23.5 \pm 8.4 \\
25.5 \pm 10.3\end{array}$ & $\begin{array}{l}34.2 \pm 14 \\
29.4 \pm I I . I\end{array}$ & $\begin{array}{l}<0.001 \\
0.03\end{array}$ \\
\hline $\begin{array}{l}\text { Tumor location } \\
\text { Upper third } \\
\text { Median third } \\
\text { Lower third }\end{array}$ & $\begin{array}{l}21.8 \pm 7.2 \\
24.5 \pm 8.7 \\
24.6 \pm 9.6\end{array}$ & $\begin{array}{l}31.8 \pm 14.2 \\
32.4 \pm 13.6 \\
31 \pm 11.8\end{array}$ & $\begin{array}{l}<0.001 \\
<0.001 \\
<0.001\end{array}$ \\
\hline $\begin{array}{l}\text { T stage } \\
\text { TI } \\
\text { T2 } \\
\text { T3 } \\
\text { T4 }\end{array}$ & $\begin{array}{l}21.2 \pm 9.5 \\
25.3 \pm 5.8 \\
24.4 \pm 9.1 \\
26.2 \pm 9.4\end{array}$ & $\begin{array}{l}28.1 \pm 11.2 \\
32.4 \pm 12.5 \\
32.9 \pm 13 \\
33.3 \pm 13.8\end{array}$ & $\begin{array}{l}<0.001 \\
0.014 \\
<0.001 \\
0.096\end{array}$ \\
\hline $\begin{array}{c}\text { N stage } \\
\text { N0 } \\
\text { NI } \\
\text { N2 } \\
\text { N3 }\end{array}$ & $\begin{array}{l}23 \pm 8.7 \\
21.3 \pm 8 \\
24.3 \pm 7.3 \\
26.4 \pm 10.2\end{array}$ & $\begin{array}{l}29.1 \pm 12.3 \\
31.2 \pm 12.4 \\
31.1 \pm 12.1 \\
36.4 \pm 12.6\end{array}$ & $\begin{array}{l}<0.001 \\
<0.001 \\
0.005 \\
<0.001\end{array}$ \\
\hline $\begin{array}{l}\text { Pathological stage } \\
\text { I } \\
\text { II } \\
\text { III }\end{array}$ & $\begin{array}{l}22.2 \pm 8.8 \\
22.7 \pm 8.3 \\
25.8 \pm 9.1\end{array}$ & $\begin{array}{l}28.6 \pm 11.4 \\
3| \pm| 3.1 \\
34.5 \pm 12.6\end{array}$ & $\begin{array}{l}<0.001 \\
<0.001 \\
<0.001\end{array}$ \\
\hline
\end{tabular}

Abbreviation: BMI, body mass index.

$0.319(0.258)$ in the EBS group (Figure 5). The PSI group was superior to the PS group, which was superior to the EBS group in terms of the numbers of lymph nodes harvested, while the LNR was lowest in the PSI group, followed by the PS and EBS groups. This suggests that
PSI harvested lymph nodes more effectively than PS and EBS, with benefits in terms of accurate acquisition of positive lymph nodes.

\section{Discussion}

Various factors can affect lymph node harvesting in gastrectomy. Enlargement of the lymphadenectomy field in radical gastrectomy was shown to result in a significant increase in the number of lymph nodes harvested, such that total gastrectomy resulted in the dissection of more lymph nodes than subtotal gastrectomy. Similarly, Smith et al showed that D2 lymphadenectomy is associated with harvesting an average of 25.2 lymph nodes, while D1 lymph node dissection only harvests an average of 12.4 lymph nodes. ${ }^{14}$ Several studies demonstrated that the surgeon's experience had a direct impact on the number of lymph nodes harvested after surgery. ${ }^{15-17}$ Obesity can affect lymph node harvesting during gastric cancer surgery, and fewer lymph nodes were harvested in patients with a $\mathrm{BMI} \geq 27$, compared with men with a BMI $<25$ or women with a BMI $<22 .{ }^{18}$ Obesity may thus have a negative impact on lymph node harvesting by increasing the difficulties of lymphadenectomy and lymph node sorting. Tumor status also affects lymph node harvesting. The number of lymph nodes harvested was affected by $T$ stage, with higher $\mathrm{T}$ staging associated with more lymph nodes being harvested. ${ }^{19}$ Individual preferences of pathologists in terms of lymph node sorting methods were considered to be an important factor affecting the number of lymph nodes harvested. ${ }^{20}$ Hanna et al pointed out that, under certain operative procedures, the number of lymph nodes harvested increased in line with the proportion of smaller lymph nodes. ${ }^{20}$ Notably, about $40 \%$ of positive lymph nodes had a diameter of $<5 \mathrm{~mm} .{ }^{21}$ The loss of small positive lymph nodes may thus affect TNM staging, with subsequent impacts on postoperative adjuvant therapy and the evaluation of patient prognosis.

The number of positive lymph nodes can be regarded as an independent predictor of postoperative prognosis in gastric cancer. ${ }^{22}$ However, whether the guideline of 'at least 15 lymph nodes' is adequate for accurate pathological staging and prognostic evaluation remains controversial, ${ }^{10,11}$ and notably the guidelines did not distinguish between total and subtotal gastrectomy, which have different extents of lymph node dissection. Lu et al found that harvesting $\geq 16$ and $\geq 21$ lymph nodes as standard practice was more conducive to evaluating the prognosis in patients undergoing distal and total gastrectomy, respectively. ${ }^{23}$ 
Table 3 Gastric Cancer-Relevant Variables In The PS Group And PSI Group

\begin{tabular}{|c|c|c|c|}
\hline & PS Group ( $N=59)$ & PSI Group $(\mathrm{N}=59)$ & $P$ value \\
\hline \multicolumn{4}{|l|}{ Patient-related data } \\
\hline Male, n (\%) & 42 (7I.2\%) & 47 (79.7\%) & 0.285 \\
\hline Female, n (\%) & $17(28.8 \%)$ & $12(20.3 \%)$ & \\
\hline Age (years) & $56.4 \pm 12.6$ & $58.4 \pm 13.6$ & 0.319 \\
\hline HOD (days) & $16.9 \pm 4.5$ & $16.7 \pm 4.7$ & 0.797 \\
\hline POD (days) & $10.6 \pm 2.6$ & $10.2 \pm 2.1$ & 0.73 \\
\hline BMI $\left(\mathrm{kg} / \mathrm{m}^{2}\right)$ & $23.7 \pm 3.5$ & $24.2 \pm 3.8$ & 0.429 \\
\hline \multicolumn{4}{|l|}{ Surgery-related data } \\
\hline Surgeon's experience ( $\geq 15$ years), $n(\%)$ & 48 (8I.4\%) & 45 (76.3\%) & 0.499 \\
\hline \multicolumn{4}{|l|}{ Gastrectomy selection, n (\%) } \\
\hline Subtotal & $36(61 \%)$ & $32(54.2 \%)$ & 0.456 \\
\hline Total & $23(39 \%)$ & 27 (45.8\%) & \\
\hline \multicolumn{4}{|l|}{ Mode of operation, n (\%) } \\
\hline Open & $29(49.2 \%)$ & 25 (42.4\%) & 0.46 \\
\hline Laparoscopic & $30(50.8 \%)$ & $34(57.6 \%)$ & \\
\hline Duration of operation (min) & $227.4 \pm 61.5$ & $241.2 \pm 59.3$ & 0.159 \\
\hline Surgical blood loss (mL) & $232.2 \pm 181.7$ & $193.2 \pm 120.5$ & 0.585 \\
\hline \multicolumn{4}{|l|}{ Pathology-related data } \\
\hline Tumor size $(\mathrm{cm})$ & $4.7 \pm 4.3$ & $4.5 \pm 2.6$ & 0.605 \\
\hline \multicolumn{4}{|l|}{ Tumor location, $\mathrm{n}(\%)$} \\
\hline Upper third & $12(20.3 \%)$ & $17(28.8 \%)$ & 0.128 \\
\hline Median third & $23(39 \%)$ & $13(22 \%)$ & \\
\hline Lower third & $24(40.7 \%)$ & 29 (49.2\%) & \\
\hline \multicolumn{4}{|l|}{ T stage, $n(\%)$} \\
\hline TI & $10(16.9 \%)$ & $9(15.3 \%)$ & 0.986 \\
\hline $\mathrm{T} 2$ & $12(20.3 \%)$ & $12(20.3 \%)$ & \\
\hline $\mathrm{T} 3$ & $32(54.2 \%)$ & $32(54.2 \%)$ & \\
\hline $\mathrm{T} 4$ & $5(8.5 \%)$ & $6(10.2 \%)$ & \\
\hline \multicolumn{4}{|l|}{$\mathrm{N}$ stage, n (\%) } \\
\hline No & 20 (33.9\%) & 23 (39\%) & 0.922 \\
\hline $\mathrm{NI}$ & $9(15.3 \%)$ & $9(15.3 \%)$ & \\
\hline N2 & $9(15.3 \%)$ & 7 (II.8\%) & \\
\hline N3 & 21 (35.6\%) & 20 (33.9\%) & \\
\hline \multicolumn{4}{|l|}{ Histological classification, n (\%) } \\
\hline $\mathrm{GI}+\mathrm{G} 2$ & 21 (35.6\%) & $23(39 \%)$ & 0.703 \\
\hline G3 & 38 (64.4\%) & $36(61 \%)$ & \\
\hline \multicolumn{4}{|l|}{ Pathological stage, n (\%) } \\
\hline I & II (I8.6\%) & 17 (28.8\%) & 0.259 \\
\hline II & 21 (35.6\%) & $14(23.7 \%)$ & \\
\hline III & 27 (45.8\%) & $28(47.5 \%)$ & \\
\hline
\end{tabular}

Abbreviations: HOD, hospitalization days; POD, postoperative days; BMI, body mass index.

Recent studies have shown a correlation between postoperative survival time and the number of lymph nodes harvested in gastric cancer patients. ${ }^{24,25}$ The results of a study have shown that the average survival time was longer in patients with more lymph nodes harvested, using 25 and 40 lymph nodes as the harvesting rules. ${ }^{11}$ Deng et al investigated the impact of the number of examined lymph nodes on the prognosis of gastric 
A

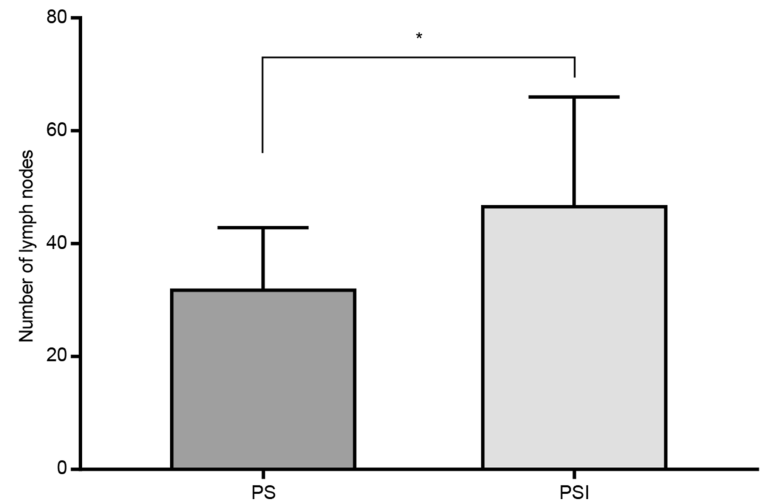

C

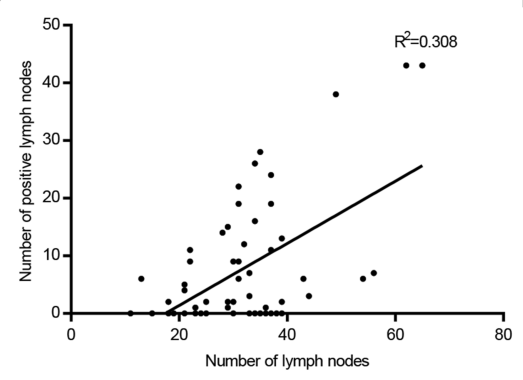

D

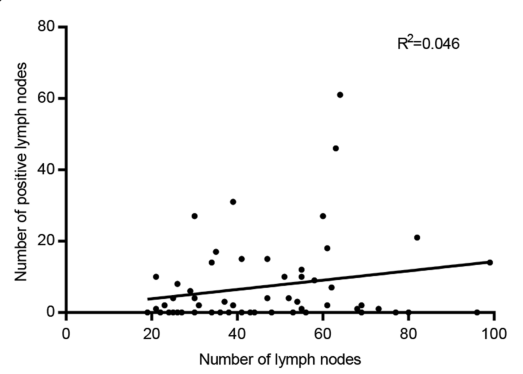

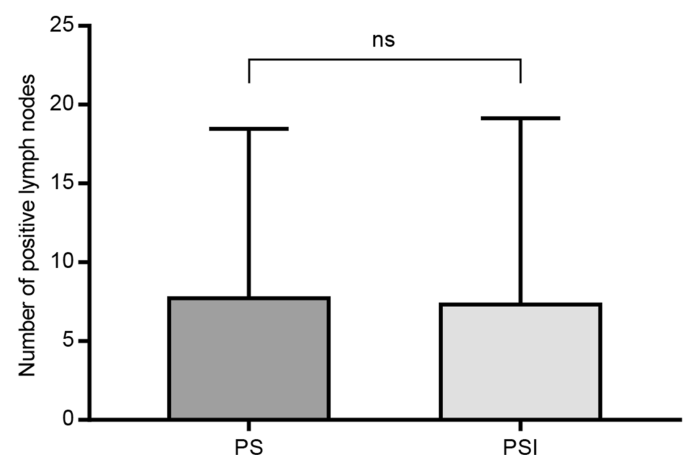

E

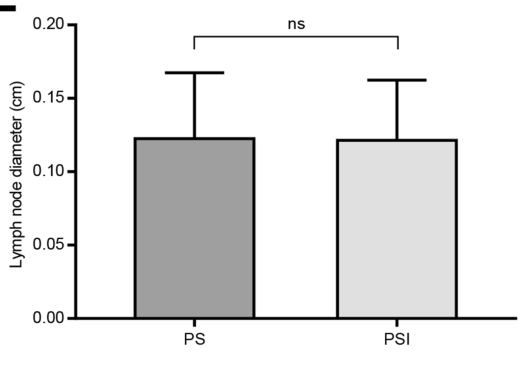

F
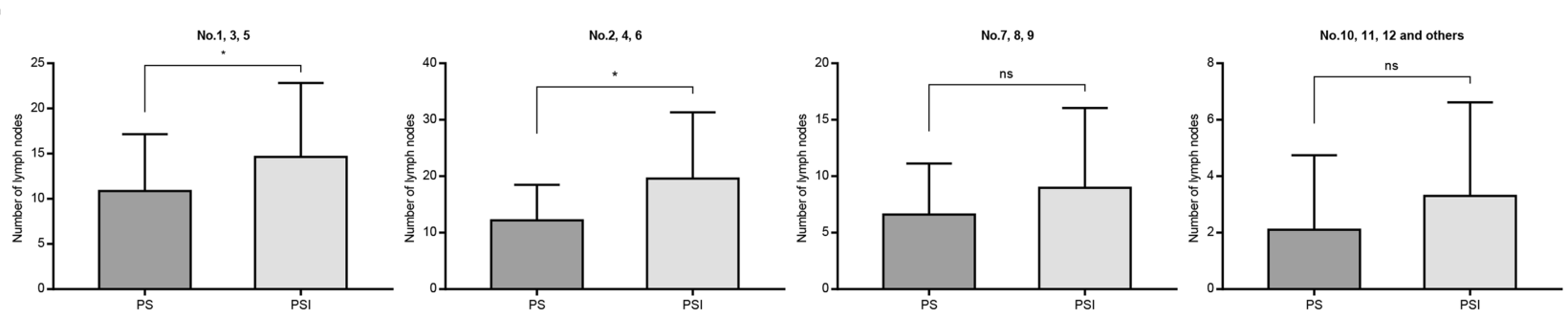

Figure 3 Lymph nodes harvested in PS and PSI groups. (A and B) Average number of lymph nodes harvested in PS and PSI groups (*P<0.05). (C and $\mathbf{D})$ Correlation between the number of lymph node harvested and positive lymph node harvested in PS and PSI groups. (E) The minimum average lymph node diameter in PS and PSI groups. (F) Average number of lymph nodes harvested from different lymph node stations $(* P<0.05)$.

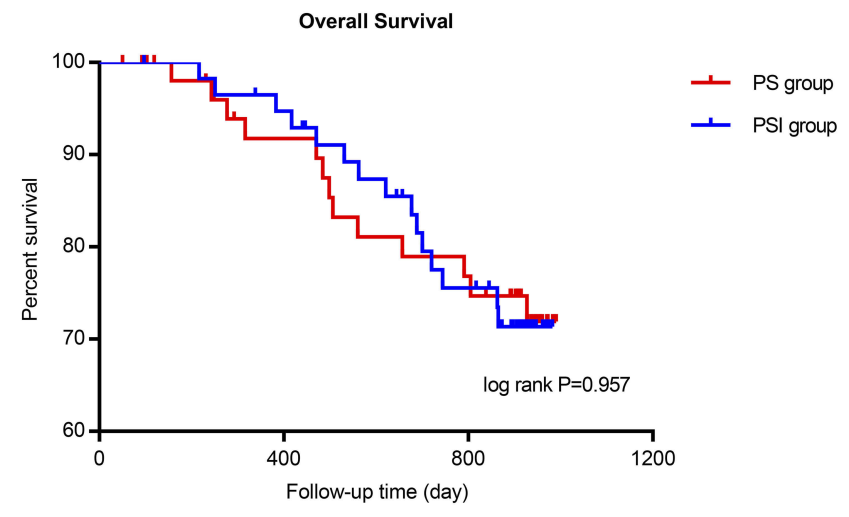

Figure 4 The overall survival curve in PS and PSI groups.

cancer patients after radical resection based on clinicopathological data for 2455 patients, ${ }^{8}$ and found that the accuracy of cancer staging, as well as patient survival, increased with increasing number of examined lymph nodes. Hsu et al accordingly indicated that the number of examined lymph nodes was an independent prognostic factor for disease-specific overall survival based on 1030 lymph node-negative gastric cancer cases. ${ }^{26}$ Furthermore, lymph node micrometastasis has recently been recognized to occur in gastric cancer, ${ }^{27}$ and lymphovascular invasion (LVI) was suggested for consideration as an important adjuvant prognostic factor, especially in pN0 cases with insufficient lymph nodes examined. ${ }^{28}$ Although the clinical significance of micrometastasis and LVI remains unclear, they are closely related to further treatment planning and patient prognosis after surgery, which also rely on lymph node harvesting. Overall, harvesting the maximum possible number of lymph nodes may benefit patients. 
Table 4 Lymph Node Counts Stratified By Relevant Variables In The PS Group And PSI Group

\begin{tabular}{|c|c|c|c|}
\hline & $\begin{array}{l}\text { PS Group } \\
(\mathrm{N}=59)\end{array}$ & $\begin{array}{l}\text { PSI Group } \\
(\mathrm{N}=59)\end{array}$ & $\begin{array}{l}\mathbf{P} \\
\text { value }\end{array}$ \\
\hline Lymph node counts & $31.8 \pm 11.1$ & $46.5 \pm 19.4$ & $<0.001$ \\
\hline Male & $31.8 \pm 11$ & $49 \pm 20$ & $<0.001$ \\
\hline Female & $31.6 \pm 11.6$ & $36.6 \pm 13.7$ & 0.297 \\
\hline $\mathrm{Age}<60$ & $32.5 \pm 11.3$ & $39.4 \pm 19.4$ & 0.381 \\
\hline $\mathrm{Age} \geq 60$ & $31 \pm 10.9$ & $51 \pm 18.3$ & $<0.001$ \\
\hline BMI $<27$ & $32.2 \pm 11.3$ & $47.9 \pm 20.4$ & $<0.001$ \\
\hline $\mathrm{BMI} \geq 27$ & $28.8 \pm 9.3$ & $4 I .1 \pm 14.4$ & 0.047 \\
\hline $\begin{array}{l}\text { Surgeon's experience } \\
\text { ( } \geq 15 \text { years) }\end{array}$ & $31.7 \pm 11.6$ & $44.6 \pm 19.6$ & 0.002 \\
\hline $\begin{array}{l}\text { Surgeon's experience } \\
(<15 \text { years })\end{array}$ & $31.9 \pm 9$ & $52.8 \pm 18.1$ & 0.002 \\
\hline $\begin{array}{l}\text { Gastrectomy selection } \\
\text { Subtotal } \\
\text { Total }\end{array}$ & $\begin{array}{l}30 \pm 11.3 \\
34.4 \pm 10.4\end{array}$ & $\begin{array}{l}42 \pm 16.5 \\
51.9 \pm 21.6\end{array}$ & $\begin{array}{l}0.001 \\
0.001\end{array}$ \\
\hline $\begin{array}{l}\text { Mode of operation } \\
\text { Open } \\
\text { Laparoscopic }\end{array}$ & $\begin{array}{l}31 \pm 11.4 \\
32.4 \pm 10.9\end{array}$ & $\begin{array}{l}44.8 \pm 19.5 \\
47.8 \pm 19.6\end{array}$ & $\begin{array}{l}0.004 \\
<0.001\end{array}$ \\
\hline $\begin{array}{l}\text { Tumor location } \\
\text { Upper third } \\
\text { Median third } \\
\text { Lower third }\end{array}$ & $\begin{array}{l}27.2 \pm 8.6 \\
32.6 \pm 11.6 \\
33.2 \pm 11.4\end{array}$ & $\begin{array}{l}52.2 \pm 23.4 \\
46.2 \pm 18.4 \\
43.4 \pm 17.2\end{array}$ & $\begin{array}{l}0.001 \\
0.028 \\
0.034\end{array}$ \\
\hline $\begin{array}{l}\text { T stage } \\
\text { T1 } \\
\text { T2 } \\
\text { T3 } \\
\text { T4 }\end{array}$ & $\begin{array}{l}27.5 \pm 11.8 \\
31.7 \pm 10.7 \\
33 \pm 11.8 \\
32.4 \pm 4.7\end{array}$ & $\begin{array}{l}40.8 \pm 18.2 \\
48.1 \pm 19.4 \\
47.5 \pm 19.8 \\
46.7 \pm 22.9\end{array}$ & $\begin{array}{l}0.073 \\
0.018 \\
0.002 \\
0.191\end{array}$ \\
\hline $\begin{array}{l}\mathrm{N} \text { stage } \\
\text { N0 } \\
\text { NI } \\
\text { N2 } \\
\text { N3 }\end{array}$ & $\begin{array}{l}27.1 \pm 8.8 \\
28.2 \pm 6.5 \\
33.7 \pm 13.5 \\
36.9 \pm 11.7\end{array}$ & $\begin{array}{l}42.9 \pm 20.8 \\
48.9 \pm 20.6 \\
39.1 \pm 11.8 \\
52.2 \pm 18.9\end{array}$ & $\begin{array}{l}0.002 \\
0.017 \\
0.41 \\
0.008\end{array}$ \\
\hline $\begin{array}{l}\text { Pathological stage } \\
\text { I } \\
\text { II } \\
\text { III }\end{array}$ & $\begin{array}{l}27.4 \pm 10.5 \\
30.1 \pm 9.4 \\
34.9 \pm 11.9\end{array}$ & $\begin{array}{l}44.1 \pm 19.8 \\
48.2 \pm 21.6 \\
47.1 \pm 18.7\end{array}$ & $\begin{array}{l}0.016 \\
0.009 \\
0.02\end{array}$ \\
\hline
\end{tabular}

Abbreviation: BMI, body mass index.

Various histopathological techniques have been investigated to increase lymph node harvesting in gastric cancer specimens. Candela et al reported a fat-clearing method using alcohol and cedar oil, which showed obvious advantages for detecting small-volume lymph nodes. This method also

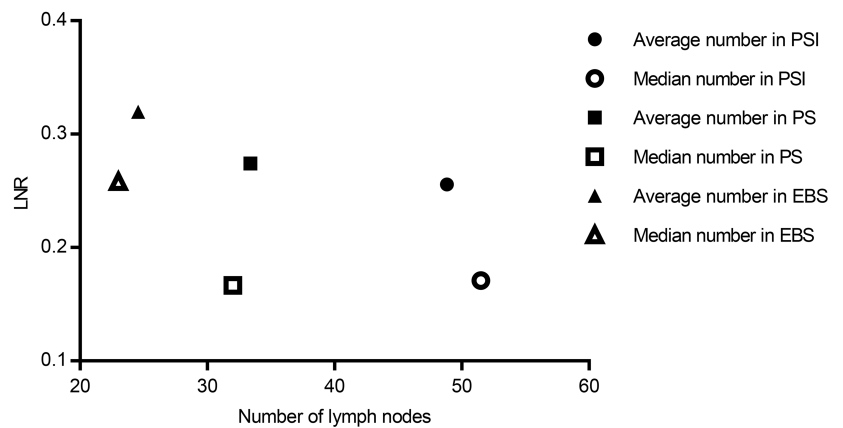

Figure $\mathbf{5}$ The average and median numbers of lymph nodes harvested and LNRs in EBS, PS, and PSI groups.

improved the precision of staging as well as increasing the number of lymph nodes harvested from 20 to 36, which was higher than that reported in Japan in the same period. ${ }^{29}$ Aoyama et al increased the average number and efficiency of lymph node harvesting using methylene blue as a staining material. ${ }^{30} \mathrm{~A}$ meta-analysis of 27 studies involving fat-clearing and methylene blue staining concluded that these two techniques could improve lymph node harvesting compared with the traditional method, and also harvested more positive lymph nodes. ${ }^{31}$ Carbon nanoparticles can be selectively absorbed by the lymphatics and can provide indications for lymphadenectomy, as well as acting as a tracer to mark the location of lymph nodes, with benefits for surgery as well as pathological examination. A prospective randomized controlled trial showed that carbon nanoparticles increased the overall number of lymph nodes harvested and improved the harvesting of small lymph nodes. ${ }^{32}$

The PSI method used in this study involved isolating lymph nodes immediately after surgery, based on visualization and palpation by the surgeon and/or assistant. The sorted lymph nodes and the remaining fat tissues were then sent to the Pathology Department for subsequent processing. The average number of lymph nodes harvested in the PSI group was significantly superior to that in the PS group in the prospective study, while the number harvested in the PS group was significantly higher than in the EBS group in the retrospective study. Some researchers pointed out that at least 25 lymph nodes should be harvested in patients with advanced gastric cancer. ${ }^{33,34}$ Accordingly, we demonstrated a significant difference in the proportions of patients in whom least 25 lymph nodes were harvested among these three groups. A study of 222 cases at the Memorial Sloan-Kettering Cancer Center showed that ex vivo lymphadenectomy could significantly increase the number of lymph nodes harvested. ${ }^{35}$ The 
investigators divided perigastric adipose tissue into 10-12 discrete lymph node packets correlating with lymph node stations, immediately following gastrectomy and before submitting them to the Pathology Department, similar to the PS process in the current study, and confirmed the effectiveness of packet submission of gastric cancer specimens. We also found significant differences in the minimum average lymph node diameter between EBS and PS groups but not between PS and PSI groups, which might be attributable to measurement of lymph node diameter in our center being accurate only to $0.1 \mathrm{~cm}$. The LNR is the ratio between the positive lymph nodes and the total lymph nodes examined, which has been shown to be a prognostic indicator for gastric cancer after surgery. ${ }^{36}$ Patients are predicted to acquire a different prognosis from using a different LNR cutoff. ${ }^{37}$ In this study each specific subgroup holds a different LNR corresponding to a different number of lymph nodes harvested, which might indicate accurate acquisition of positive lymph nodes in subgroups with a high number of lymph nodes harvested combined with low LNR.

This study had several limitations, including bias resulting from the retrospective nature of part of the study. However, the retrospective study included a relatively large sample size collected over a relatively short time period. The retrospective study detected differences between the EBS and PS groups in terms of tumor location, mode of operation, duration of operation, and surgical blood loss. The time span of the collected cases meant that there were more cases of open surgery and fewer of laparoscopic surgery during the early period, when EBS was carried out more frequently than PS, while the use of laparoscopic surgery subsequently increased and PS became more popular, resulting in the difference between the two groups. Furthermore, there was no significant difference in the numbers of lymph nodes harvested in women or in patients $<60$ years old in the prospective study, which may be attributed to potential bias in enrolled patients. Some studies noted that the number of lymph nodes harvested correlated with postoperative patient prognosis. $^{24,25}$ Nevertheless, the survival database revealed no statistical difference in PS and PSI groups, which deserves further investigation. Bias may have resulted from limited follow-up time and number of enrolled cases in the prospective study.

\section{Conclusion}

In summary, this study demonstrates that PSI following curative gastrectomy in patients with gastric cancer is associated with harvest of more lymph nodes and a lower LNR at pathological examination than either PS or EBS, while PS was preferable to EBS in these respects. However, further studies are needed to clarify the impact of PSI on the prognosis and stage-specific survival of patients with gastric cancer.

\section{Acknowledgments}

We are grateful to Wentao Liang and Kai Liang for their assistance with lymph node sorting. We also express our sincere appreciation to Dr. Yunxia An for her help in pathology-related aspects of this work. This study was supported by the National Natural Science Foundation of China (No. $81672319,81773135)$ and the Beijing Municipal Science and Technology Plan projects (Z161100000516237).

\section{Disclosure}

Dr. Hongqing Xi, Dr. Bo Wei and Dr. Lin Chen are the owner of a license of a patent Lymph nodes sorting box. The authors report no other conflicts of interest related to this work.

\section{References}

1. Bray F, Ferlay J, Soerjomataram I, Siegel RL, Torre LA, Jemal A. Global cancer statistics 2018: GLOBOCAN estimates of incidence and mortality worldwide for 36 cancers in 185 countries. CA Cancer J Clin. 2018;68(6):394-424. doi:10.3322/caac.21492.

2. Pilleron S, Sarfati D, Janssen-Heijnen M, et al. Global cancer incidence in older adults, 2012 and 2035: a population-based study. Int $J$ Cancer. 2019;144(1):49-58. doi:10.1002/ijc.31664

3. Hartgrink HH, Jansen EP, van Grieken NC, van de Velde CJ. Gastric cancer. Lancet (London, England). 2009;374(9688):477-490. doi:10.1016/S0140-6736(09)60617-6

4. Abe N, Watanabe T, Suzuki K, et al. Risk factors predictive of lymph node metastasis in depressed early gastric cancer. Am $J$ Surg. 2002;183(2):168-172. doi:10.1016/S0002-9610(01)00860-1

5. Kong P, Wu R, Yang C, et al. Prognostic impact of the signet ring cell type in node-negative gastric cancer. Sci Rep. 2016;6:26313. doi: $10.1038 /$ srep26313

6. Jian-Hui C, Shi-Rong C, Hui W, et al. Prognostic value of three different lymph node staging systems in the survival of patients with gastric cancer following D2 lymphadenectomy. Tumour Biol. 2016;37(8):11105-11113. doi:10.1007/s13277-015-4191-7

7. Toth D, Plosz J, Torok M. Clinical significance of lymphadenectomy in patients with gastric cancer. World J Gastrointest Oncol. 2016;8 (2):136-146. doi:10.4251/wjgo.v8.i2.136

8. Deng J, Yamashita H, Seto Y, Liang H. Increasing the number of examined lymph nodes is a prerequisite for improvement in the accurate evaluation of overall survival of node-negative gastric cancer patients. Ann Surg Oncol. 2017;24(3):745-753. doi:10.1245/ s10434-016-5513-8

9. Wohnrath DR, Araujo RLC. D2 lymphadenectomy for gastric cancer as an independent prognostic factor of 10-year overall survival. Eur $J$ Surg Oncol. 2019;45(3):446-453. doi:10.1016/j.ejso.2018.10.538

10. Bouvier AM, Haas O, Piard F, Roignot P, Bonithon-Kopp C, Faivre J. How many nodes must be examined to accurately stage gastric carcinomas? Results from a population based study. Cancer. 2002;94(11):2862-2866. doi:10.1002/cncr.10550 
11. Kim YI. Does the retrieval of at least 15 lymph nodes confer an improved survival in patients with advanced gastric cancer? J Gastric Cancer. 2014;14(2):111-116. doi:10.5230/jgc.2014.14.2.111

12. Komatsu S, Ichikawa D, Nishimura M, et al. Evaluation of prognostic value and stage migration effect using positive lymph node ratio in gastric cancer. Eur J Surg Oncol. 2017;43(1):203-209. doi:10.1016/j. ejso.2016.08.002

13. Kelly KJ, Selby L, Chou JF, et al. Laparoscopic versus open gastrectomy for gastric adenocarcinoma in the west: a case-control study. Ann Surg Oncol. 2015;22(11):3590-3596. doi:10.1245/s10434-015-4381-y

14. Smith BR, Stabile BE. Aggressive D2 lymphadenectomy is required for accurate pathologic staging of gastric adenocarcinoma. Am Surg. 2006;72(10):849-852.

15. Kang SY, Lee SY, Kim CY, Yang DH. Comparison of learning curves and clinical outcomes between laparoscopy-assisted distal gastrectomy and open distal gastrectomy. J Gastric Cancer. 2010;10(4):247253. doi:10.5230/jgc.2010.10.4.247

16. Zhou D, Quan Z, Wang J, Zhao M, Yang Y. Laparoscopic-assisted versus open distal gastrectomy with D2 lymph node resection for advanced gastric cancer: effect of learning curve on short-term outcomes. a meta-analysis. J Laparoendosc Adv Surg Tech A. 2014;24 (3):139-150. doi:10.1089/lap.2013.0481

17. Zhao LY, Zhang WH, Sun Y, et al. Learning curve for gastric cancer patients with laparoscopy-assisted distal gastrectomy: 6-year experience from a single institution in Western China. Medicine. 2016;95 (37):e4875. doi:10.1097/MD.0000000000004875

18. Kodera Y, Ito S, Yamamura Y, et al. Obesity and outcome of distal gastrectomy with D2 lymphadenectomy for carcinoma. HepatoGastroenterology. 2004;51(58):1225-1228.

19. Dikken JL, van Grieken NC, Krijnen P, et al. Preoperative chemotherapy does not influence the number of evaluable lymph nodes in resected gastric cancer. Eur J Surg Oncol. 2012;38(4):319-325. doi:10.1016/j.ejso.2011.12.016

20. Hanna GB, Amygdalos I, Ni M, et al. Improving the standard of lymph node retrieval after gastric cancer surgery. Histopathology. 2013;63(3):316-324. doi:10.1111/his.12167

21. Noda N, Sasako M, Yamaguchi N, Nakanishi Y. Ignoring small lymph nodes can be a major cause of staging error in gastric cancer. Br J Surg. 1998;85(6):831-834. doi:10.1046/j.1365-2168.1998.00691.x

22. Nakamura K, Morisaki T, Sugitani A, et al. An early gastric carcinoma treatment strategy based on analysis of lymph node metastasis. Cancer. 1999;85(7):1500-1505.

23. Lu J, Wang $\mathrm{W}$, Zheng $\mathrm{CH}$, et al. Influence of total lymph node count on staging and survival after gastrectomy for gastric cancer: an analysis from a two-institution database in China. Ann Surg Oncol. 2017;24(2):486-493. doi:10.1245/s10434-016-5494-7

24. Morgan JW, Ji L, Friedman G, Senthil M, Dyke C, Lum SS. The role of the cancer center when using lymph node count as a quality measure for gastric cancer surgery. JAMA Surg. 2015;150(1):37-43. doi:10.1001/jamasurg.2014.678
25. Deutsch GB, O'Connor V, Sim MS, Lee JH, Bilchik AJ. Incorporating surgical quality into the AJCC 7 th edition improves staging accuracy in gastric cancer. Ann Surg Oncol. 2015;22(1):1116. doi:10.1245/s10434-014-4004-z

26. Hsu JT, Lin CJ, Sung CM, et al. Prognostic significance of the number of examined lymph nodes in node-negative gastric adenocarcinoma. Eur J Surg Oncol. 2013;39(11):1287-1293. doi:10.1016/j. ejso.2013.07.183

27. Ru Y, Zhang L, Chen Q, et al. Detection and clinical significance of lymph node micrometastasis in gastric cardia adenocarcinoma. $J$ Int Med Res. 2012;40(1):293-299. doi:10.1177/147323001204000129

28. Zhang CD, Ning FL, Zeng XT, Dai DQ. Lymphovascular invasion as a predictor for lymph node metastasis and a prognostic factor in gastric cancer patients under 70 years of age: a retrospective analysis. Int J Surg. 2018;53:214-220. doi:10.1016/j.ijsu.2018.03.073

29. Candela FC, Urmacher C, Brennan MF. Comparison of the conventional method of lymph node staging with a comprehensive fatclearing method for gastric adenocarcinoma. Cancer. 1990;66 (8):1828-1832. doi:10.1002/1097-0142(19901015)66:8<1828::aidcncr2820660830>3.0.co;2-z

30. Aoyama T, Fujikawa H, Cho H, et al. A methylene blue-assisted technique for harvesting lymph nodes after radical surgery for gastric cancer: a prospective, randomized, controlled study. Am J Surg Pathol. 2015;39(2):266-273. doi:10.1097/PAS.0000000000000336

31. Abbassi-Ghadi N, Boshier PR, Goldin R, Hanna GB. Techniques to increase lymph node harvest from gastrointestinal cancer specimens: a systematic review and meta-analysis. Histopathology. 2012;61 (4):531-542. doi:10.1111/j.1365-2559.2012.04357.x

32. Li Z, Ao S, Bu Z, et al. Clinical study of harvesting lymph nodes with carbon nanoparticles in advanced gastric cancer: a prospective randomized trial. World J Surg Oncol. 2016;14:88. doi:10.1186/s12957016-0835-3

33. De Marco C, Biondi A, Ricci R. N staging: the role of the pathologist. Transl Gastroenterol Hepatol. 2017;2:10. doi:10.21037/ $\operatorname{tgh} .2017 .01 .02$

34. Chen HN, Chen XZ, Zhang WH, et al. Necessity of harvesting at least 25 lymph nodes in patients with stage N2-N3 resectable gastric cancer: a 10-year, single-institution cohort study. Medicine. 2015;94 (10):e620. doi:10.1097/MD.0000000000000620

35. Afaneh C, Levy A, Selby L, et al. Ex vivo lymphadenectomy during gastrectomy for adenocarcinoma optimizes lymph node yield. $J$ Gastrointest Surg. 2016;20(1):165-171. discussion 171. doi:10.1007/s11605-015-2948-3

36. Agnes A, Biondi A, Cananzi FM, et al. Ratio-based staging systems are better than the 7 th and 8 th editions of the TNM in stratifying the prognosis of gastric cancer patients: a multicenter retrospective study. J Surg Oncol. 2019;119(7):948-957. doi:10.1002/jso.25411

37. Hou Y, Wang X, Chen J. Prognostic significance of metastatic lymph node ratio: the lymph node ratio could be a prognostic indicator for patients with gastric cancer. World J Surg Oncol. 2018;16(1):198. doi:10.1186/s12957-018-1504-5
Cancer Management and Research is an international, peer-reviewed open access journal focusing on cancer research and the optimal use of preventative and integrated treatment interventions to achieve improved outcomes, enhanced survival and quality of life for the cancer patient.
The manuscript management system is completely online and includes a very quick and fair peer-review system, which is all easy to use. Visit http://www.dovepress.com/testimonials.php to read real quotes from published authors. 